\title{
Investigation of the Effect of HATCH Score and Coronary Artery Disease Complexity on Atrial Fibrillation after On-Pump Coronary Artery Bypass Graft Surgery
}

\author{
Mesut Engin ${ }^{\mathrm{a}}$ Cihan Aydın ${ }^{\mathrm{b}}$ \\ ${ }^{a}$ Mehmet Akif İnan Training and Research Hospital, Department of Cardiovascular Surgery, University of Health

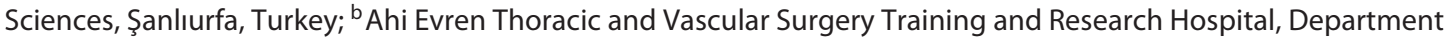 \\ of Cardiology, University of Health Sciences, Trabzon, Turkey
}

\section{Highlights of the Study}

- The SYNTAX score I is an angiographic scoring system that indicates the severity of coronary artery disease.

- The HATCH score is a scoring system calculated using clinical parameters of patients.

- Each of these clinical parameters could be a risk factor for the development of atrial fibrillation (AF).

- Here we investigated the association between the development of postoperative AF (PoAF) and the HATCH score. The SYNTAX score I and a HATCH score $>2$ are independent predictors of PoAF.

\section{Keywords}

Atrial fibrillation · HATCH score - SYNTAX score .

Coronary artery bypass surgery

\begin{abstract}
Objective: Postoperative atrial fibrillation (PoAF) is the most frequently encountered rhythm problem after coronary artery bypass graft (CABG) surgery. This situation decreases the capacity of the patients with respect to functional exercise and creates a risk for stroke. In this study, we aimed to determine the effect of coronary artery disease extensiveness and HATCH score on PoAF in patients undergoing CABG surgery with cardiopulmonary bypass. Subjects and Methods: Patients who underwent CABG between December 2014 and December 2018 were included retrospectively. Preoperative
\end{abstract}

karger@karger.com www.karger.com/mpp

Karger $\stackrel{\text { ' }}{5}$

GOPEN ACCESS
(C) 2020 The Author(s)

Published by S. Karger AG, Basel

This is an Open Access article licensed under the Creative Commons Attribution-NonCommercial-4.0 International License (CC BY-NC) (http://www.karger.com/Services/OpenAccessLicense), applicable to the online version of the article only. Usage and distribution for commercial purposes requires written permission. demographic characteristics, laboratory parameters, and operative parameters of the patients were recorded retrospectively. Results: Of the 352 patients, 274 had HATCH scores $\leq 2$ (71.1\% male, mean age: $61.7 \pm 12.4$ years), and 78 had $\mathrm{HATCH}$ scores $>2$ (69.2\% male, mean age: $65.9 \pm 11.7$ years). Significant differences were found between the 2 groups in terms of the age $(p=0.014)$, presence of hypertension $(p=0.012)$, PoAF $(p<0.001)$, and SYNTAX (synergy between percutaneous coronary intervention with taxus and cardiac surgery) score I $(p=0.001)$. A HATCH score $>2$ and SYNTAX score I were identified as independent predictors of PoAF (OR: 1.022, 95\% Cl: $1.004-1.128, p=0.032$, and OR $1.098,95 \% \mathrm{Cl} 1.035-1.164$, $p=0.002$, respectively). For predicting PoAF, the cutoff level in the ROC curve analysis was 19.7 for SYNTAX score (AUC $0.647,95 \% \mathrm{Cl} 0.581-0.714, p<0.001,72.2 \%$ sensitivity and $66.4 \%$ specificity), and the cutoff level for HATCH score was 2 
(AUC $0.656,95 \% \mathrm{Cl} 0.595-0.722, p<0.001,69.4 \%$ sensitivity and $56.8 \%$ specificity) Conclusions: HATCH and SYNTAX scores are predictors of PoAF.

(C) 2020 The Author(s)

Published by S. Karger AG, Basel

\section{Introduction}

Postoperative atrial fibrillation (PoAF) is the most frequently encountered rhythm problem following coronary artery bypass graft (CABG) surgery. PoAF may emerge in $10-40 \%$ of the cases in the postoperative term $[1,2]$. This situation decreases the capacity of the patients with respect to functional exercise and creates a risk for stroke [3]. As a result, PoAF prolongs hospital stay of the patients.

The SYNTAX (synergy between percutaneous coronary intervention with taxus and cardiac surgery) score I is an angiographic scoring system that indicates the severity of coronary artery disease. It is commonly utilized to assess long-term results after percutaneous coronary interventions and CABG surgery $[4,5]$. In patients undergoing $\mathrm{CABG}$, extensive coronary artery disease has been shown to be an additional risk factor for the occurrence of PoAF [6].

The HATCH score is a scoring system that can easily be calculated using clinical parameters (Table 1). As each of these clinical parameters could be a risk factor for AF development, the HATCH score is a significant parameter for predicting PoAF. It has been shown that this scoring system can predict $\mathrm{AF}$ recurrence after ablation therapy [7]. It has also been used to express the risk of PoAF after coronary bypass operations [8].

In this study, we aimed to determine the role of HATCH and SYNTAX scoring systems in predicting PoAF in patients undergoing CABG surgery with cardiopulmonary bypass and to investigate the relationship between both scoring systems.

\section{Subjects and Methods}

Three hundred and fifty-two consecutive patients who underwent isolated CABG between December 2014 and December 2018 were included in this study. The local ethics committee approved the study. Data were retrospectively obtained from the hospital registry and patient files. Preoperative demographic characteristics, laboratory parameters, operative parameters, SYNTAX scores, and HATCH scores were recorded. Patients with preoperative AF and mild mitral insufficiency or worse, and a left atrial diameter $>40 \mathrm{~mm}$ on preoperative echocardiography as well as those who used amiodarone and underwent emergency operations were excluded from the study.
Table 1. HATCH score parameters

\begin{tabular}{ll}
\hline Variables & Points \\
\hline Ejection fraction $\leq 40$ & 2 \\
Transient ischemic attack/stroke & 2 \\
Age $>75$ years & 1 \\
Hypertension & 1 \\
Chronic obstructive pulmonary disease & 1 \\
\hline
\end{tabular}

\section{Diagnosis of PoAF}

All patients were observed in the intensive care unit (ICU) with continuous heart rhythm and invasive blood pressure monitoring. Furthermore, 12-lead electrocardiography (ECG) was taken during the ICU period. The 12-lead ECG was performed when the patients had complaints such as palpitation, dyspnea, or angina pectoris. AF was verified via 12-lead ECG. The diagnosis of AF was based on guidelines of the European Society of Cardiology [9] . Postoperative AF was defined as irregular or fibrillatory waves in place of typical $p$ waves on ECG. An AF episode $>60 \mathrm{~s}$ was considered a PoAF.

\section{Calculation of SYNTAX Score}

Coronary angiography was performed using the Judkins method. All lesions causing stenosis of $\geq 50 \%$ in a coronary artery with a diameter of $\geq 1.5 \mathrm{~mm}$ were involved in the SYNTAX score calculation. For this purpose, score I calculator version 2.28 (Cardialysis, Boston Scientific; available at www.syntaxscore.com) was utilized.

\section{Laboratory Measurements}

Preprandial blood samples were obtained from an antecubital vein at the time of admission. The sample was collected in tubes containing ethylenediaminetetraacetic acid and was used for automatic blood count with the usual hospital procedures. An automated hematological analyzer was used for measuring hematological parameters (Coulter LH 780 Analyzer, CA, USA).

\section{Statistical Analysis}

Statistical analysis was performed with SPSS (version 21.0; IBM Statistical Package for the Social Sciences Statistic Inc., Chicago, IL, USA). Descriptive statistics such as means and SD were calculated for continuous and ordinal variables. The frequencies and percentages were analyzed for nominal variables. Kolmogorov-Smirnov and Shapiro-Wilk tests were performed to analyze the normality of the data. Student $t$ and Mann-Whitney $\mathrm{U}$ tests were used to compare continuous variables with and without normal distribution between 2 groups, respectively. Nominal variables were compared using the $\chi^{2}$ test. Predictors of PoAF were defined via binary logistic regression analysis. $p<0.05$ was considered statistically significant. Receiver-operating characteristic (ROC) curve analysis was used for the prediction of PoAF, and the area under the curve (AUC) was calculated for $\mathrm{HATCH}$ and SYNTAX scores. Correlation analysis between HATCH and SYNTAX scores was performed using Spearman correlation analysis.
Engin/Aydin 
Table 2. Demographic features of the patients

\begin{tabular}{lccc}
\hline Characteristics & \multicolumn{2}{l}{ HATCH score } & \multirow{2}{*}{$p$ value } \\
\cline { 2 - 3 } & $\leq 2(n=274)$ & $>2(n=78)$ & $0.014^{\mathrm{a}}$ \\
\hline Age, years & $61.7 \pm 12.4$ & $65.9 \pm 11.7$ & 0.799 \\
Gender, male, $n(\%)$ & $195(71.1)$ & $54(69.2)$ & 0.012 \\
Hypertension, $n(\%)$ & $149(54.3)$ & $56(71.7)$ & 0.421 \\
Diabetes mellitus, $n(\%)$ & $84(30.6)$ & $18(23)$ & $0.567^{\mathrm{a}}$ \\
Ejection fraction, \%, & $48.9 \pm 9.5$ & $47.6 \pm 9.8$ & 0.173 \\
Preoperative cerebrovascular accident, $n(\%)$ & $33(12)$ & $16(20.5)$ & 0.876 \\
Preoperative PCI, $n(\%)$ & $57(20.8)$ & $18(23)$ & 0.189 \\
Chronic obstructive pulmonary disease, $n(\%)$ & $28(10.2)$ & $15(19.2)$ & 0.356 \\
Peripheral artery disease, $n(\%)$ & $22(8)$ & $8(10.2)$ & 0.757 \\
$\beta$-Blocker therapy, $n(\%)$ & $221(80.6)$ & $64(82)$ & 0.815 \\
ARB/ACE-I therapy, $n$ (\%) & $83(30.2)$ & $22(28.2)$ & $0.001^{\mathrm{b}}$ \\
SYNTAX score I & $18(12-28)$ & $18(14-35)$ & $<0.001$ \\
Postoperative atrial fibrillation $(+), n(\%)$ & $61(22.2)$ & $33(42.3)$ & $0.454^{\mathrm{a}}$ \\
Body mass index, kg/m ${ }^{2}$ & $26.56 \pm 5.48$ & $27.26 \pm 4.28$ & \\
\hline
\end{tabular}

Means \pm SD, medians (ranges), and numbers (\%) are shown. PCI, percutaneous coronary intervention; ACE-I, angiotensin-converting enzyme inhibitor; ARB, angiotensin receptor blocker. Significant values are

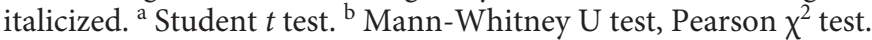

\section{Results}

Of the 352 patients, 274 had HATCH scores $\leq 2(71.1 \%$ male, mean age: $61.7 \pm 12.4$ years) and 78 had HATCH scores $>2$ (69.2\% male, mean age: $65.9 \pm 11.7$ years). Significant differences were found between the 2 groups in terms of age $(p=0.014)$, presence of hypertension $(p=$ $0.012), \operatorname{PoAF}(p<0.001)$, and the SYNTAX score I ( $p=$ $0.001)$. However, there was no significant difference between the 2 groups in terms of preoperative ejection fraction, gender, $\beta$-blocker/angiotensin receptor blocker/angiotensin-converting enzyme inhibitor therapy, history of percutaneous coronary intervention, or ejection fraction. The demographic and clinical characteristics of the patients are shown in Table 2.

The comparison of laboratory measurements and operative data between the 2 groups are shown in Table 3 . The groups were similar concerning laboratory and operative findings, they showed significant differences in blood urea nitrogen $(p=0.032)$ and C-reactive protein $(p=0.042)$.

PoAF was seen in 94 (26.7\%) patients. Factors related to the occurrence of PoAF were included in the logistic regression analysis. In unadjusted univariate logistic regression analysis, PoAF correlated with age, SYNTAX score, and a HATCH score $>2(p=0.036, p=0.016, p=$ 0.001 , respectively) but did not correlate with hyperten- sion, chronic obstructive pulmonary disease, body mass index, diabetes mellitus, C-reactive protein, and ejection fraction. In multivariate analysis, SYNTAX score I and a HATCH score $>2$ were identified as independent predictors of PoAF (OR 1.022, 95\% CI 1.004-1.128, $p=0.032$, and OR 1.098, 95\% CI 1.035-1.164, $p=0.002$, respectively; Table 4).

For predicting PoAF, the cutoff level in the ROC curve analysis was 19.7 for SYNTAX score (AUC 0.647, 95\% CI $0.581-0.714$, log-rank $p<0.001,72.2 \%$ sensitivity and $66.4 \%$ specificity) and 2 for HATCH score (AUC 0.656, $95 \%$ CI $0.595-0.722, \log -\operatorname{rank} p<0.001,69.4 \%$ sensitivity and $56.8 \%$ specificity; Fig. 1). A weak positive correlation was found between the HATCH and SYNTAX scores $(r=0.272, p<0.001)$

\section{Discussion}

$\mathrm{AF}$, a supraventricular arrhythmia characterized by chaotic atrial activation and associated mechanical dysfunction, is the most frequent cardiac rhythm disorder. $\mathrm{AF}$ is found in $1-2 \%$ of the population, and the prevalence is higher in the elderly (5-15\% at 80 years of age) [10]. AF may have catastrophic consequences such as heart failure, ischemic stroke, and death. 
Table 3. Laboratory and operative variables of the patients

\begin{tabular}{|c|c|c|c|}
\hline \multirow[t]{2}{*}{ Parameters } & \multicolumn{2}{|l|}{ HATCH score } & \multirow[t]{2}{*}{$p$ value } \\
\hline & $\leq 2(n=274)$ & $>2(n=78)$ & \\
\hline Hematocrit, $\%$ & $41.8 \pm 3.37$ & $39.5 \pm 3.49$ & 0.329 \\
\hline White blood cells, $10^{3} / \mu \mathrm{L}$ & $9.2 \pm 2.36$ & $9.1 \pm 2.12$ & 0.618 \\
\hline Platelets, $10^{3} / \mu \mathrm{L}$ & $230(180-400)$ & $240(185-400)$ & 0.443 \\
\hline Albumin, g/dL & $3.5 \pm 0.6$ & $3.7 \pm 0.4$ & 0.321 \\
\hline Potassium, mEq/L & $4.07 \pm 0.56$ & $4.1 \pm 0.48$ & 0.618 \\
\hline Magnesium, mg/dL & $1.79 \pm 0.34$ & $1.88 \pm 0.26$ & 0.453 \\
\hline Blood urea nitrogen, $\mathrm{mg} / \mathrm{dL}$ & $18.96 \pm 7.69$ & $21.35 \pm 7.53$ & 0.032 \\
\hline Creatinine, $\mathrm{mg} / \mathrm{dL}$ & $0.92 \pm 0.22$ & $1.0 \pm 0.27$ & 0.182 \\
\hline Free $\mathrm{T}_{3}, \mathrm{pg} / \mathrm{mL}$ & $3.17 \pm 0.8$ & $2.98 \pm 0.5$ & 0.176 \\
\hline Free $\mathrm{T}_{4}, \mathrm{ng} / \mathrm{dL}$ & $1.09 \pm 0.4$ & $1.05 \pm 0.13$ & 0.286 \\
\hline TSH, IU/mL & $3.15 \pm 4.35$ & $2.82 \pm 1.43$ & 0.596 \\
\hline C-reactive protein, $\mathrm{mg} / \mathrm{dL}$ & $7(1-28)$ & $9(1-36)$ & 0.042 \\
\hline \multicolumn{4}{|l|}{ Cholesterol, mg/dL } \\
\hline Total & $200.2 \pm 32.13$ & $197.6 \pm 30.86$ & 0.556 \\
\hline Low-density lipoprotein & $126.3 \pm 25.72$ & $122.5 \pm 24.96$ & 0.650 \\
\hline High-density lipoprotein & $40.7 \pm 4.32$ & $41.2 \pm 5.67$ & 0.884 \\
\hline Triglycerides, $\mathrm{mg} / \mathrm{dL}$ & $165.1 \pm 57.96$ & $152.8 \pm 49.69$ & 0.626 \\
\hline Cross-clamp time, $\min$ & $62(44-88)$ & $65(48-90)$ & 0.343 \\
\hline Total perfusion time, min & $88(75-140)$ & $92(78-144)$ & 0.146 \\
\hline
\end{tabular}

Means \pm SD and medians (ranges). TSH, thyrotropin-stimulating hormone; $\mathrm{T}_{3}$, triiodothyronine; $\mathrm{T}_{4}$, thyroxine. Student $t$ test and the Mann-Whitney $\mathrm{U}$ test (medians and ranges) are applied. Significant values are italicized.

Table 4. Binary logistic regression analysis to identify predictors of postoperative atrial fibrillation

\begin{tabular}{|c|c|c|c|c|c|c|}
\hline \multirow[t]{2}{*}{ Variables } & \multicolumn{3}{|c|}{ Univariate analysis } & \multicolumn{3}{|c|}{ Multivariate analysis } \\
\hline & $p$ & $\exp (B) O R$ & $95 \% \mathrm{CI}$ & $p$ & $\exp (\mathrm{B}) \mathrm{OR}$ & $95 \%$ CI \\
\hline Age & 0.036 & 1.026 & $1.002-1.150$ & 0.116 & 1.020 & $0.995-1.045$ \\
\hline Hypertension & 0.200 & 0.727 & $0.447-1.184$ & & & \\
\hline COPD & 0.116 & 0.789 & $0.542-1.004$ & & & \\
\hline Body mass index & 0.369 & 0.879 & $0.715-1.048$ & & & \\
\hline Diabetes mellitus & 0.764 & 0.648 & $0.624-0.984$ & & & \\
\hline Ejection fraction & 0.316 & 0.576 & $0.176-1.117$ & & & \\
\hline SYNTAX score I & 0.016 & 1.102 & $1.040-1.168$ & 0.032 & 1.022 & $1.004-1.128$ \\
\hline C-reactive protein & 0.342 & 0.576 & $0.152-1.622$ & & & \\
\hline HATCH score $>2$ & 0.001 & 1.010 & $0.629-1.265$ & 0.002 & 1.098 & $1.035-1.164$ \\
\hline
\end{tabular}

COPD, chronic obstructive pulmonary disease. Significant values are italicized.

After coronary bypass operations, the incidence of AF varies between 20 and $45 \%$ [11, 12]. PoAF can lead to cerebrovascular events and death, and PoAF also increases the cost of treatment by extending hospital stays [13]. Therefore, it is critical that the risk factors are determined in patients who are scheduled for operation and that necessary preventive measures are taken. Although the pathophysiology of AF is not fully understood, dilatation of the atrium, increased age-related fibrosis, structural defects in the heart, and comorbid factors (hypertension, diabetes mellitus, and chronic obstructive pulmonary disease) can play a role in AF de- 


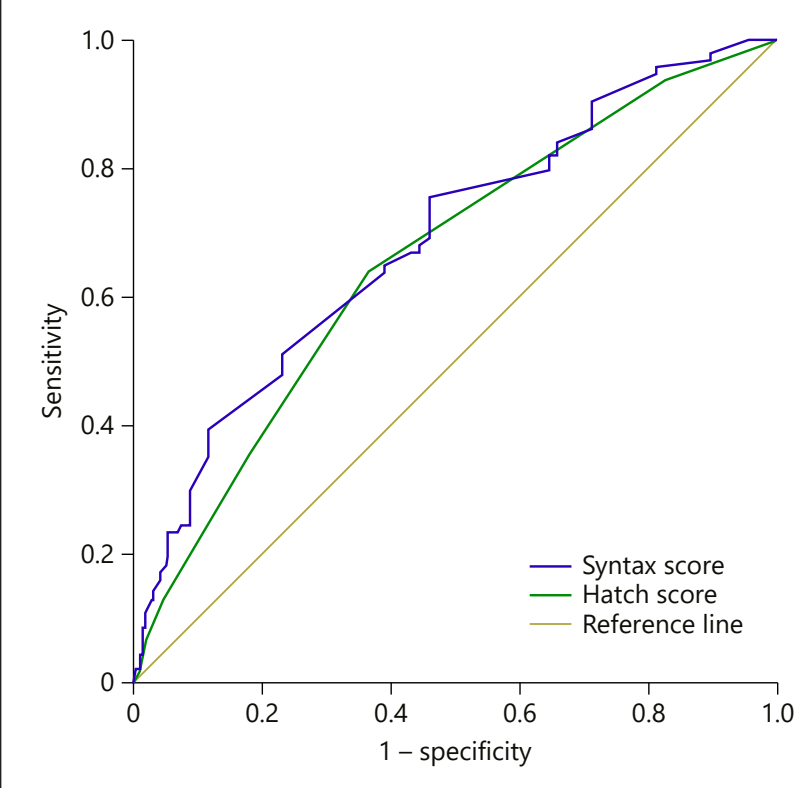

Fig. 1. Receiver-operating characteristic curve and area under the curve for SYNTAX score I and HATCH score for predicting postoperative atrial fibrillation. HATCH score: cutoff: 2, AUC: 0.656 , $p<0.001,69.4 \%$ sensitivity and $56.8 \%$ specificity; SYNTAX score: cutoff: 19.7 , AUC: $0.647, p<0.001,72.2 \%$ sensitivity and $66.4 \%$ specificity.

velopment [14]. During open-heart surgeries, intervention to the heart structure may increase AF frequency. These effects may lead to electrophysiological changes. In addition, ectopic beats from pulmonary veins may lead to PoAF [15]. Atrial ischemia may occur during cardioplegic arrest; perioperative electrolyte imbalances may also lead to PoAF [16]. The development of AF after other surgical interventions $(0.3-17.3 \%)$ is an important indicator that hemodynamic changes other than direct intervention to the heart may also be the cause of AF development [17].

The SYNTAX score I is calculated based on the localization of coronary artery disease, functional importance, and the number and complexity of stenosis [18]. This scoring system can show the risks of PoAF and significant adverse events after CABG [19]. Cerit et al. [20] studied 106 patients who underwent CABG with cardiopulmonary bypass and showed SYNTAX score to be an independent predictor of AF development. Chronic obstructive pulmonary disease, heart failure, transient ischemic attack, and diabetes mellitus were also found to be predictors of PoAF. In the same study, a SYNTAX score $>22.3$ was found to be one of the strongest predictors for the development of PoAF (AUC 0.777, 95\% CI 0.676-0.877; $86.1 \%$ sensitivity and $58.6 \%$ specificity) [20].

The HATCH score is another scoring system that includes factors such as age and heart failure (Table 1). A study followed up 670,804 patients $>20$ years of age using this scoring system. The study found that 9,174 patients (1.4\%) experienced new-onset AF during 9.0 \pm 2.2 years. They analyzed the incidence of AF using the HATCH scores of the patients. The incidence of AF was 1.5 per 1,000 patient-years. They found that increasing the $\mathrm{HATCH}$ score from 0 to 7 increased the incidence of AF from 0.8 to 57.3 per 1,000 patient-years [21]. Another study by Emren et al. [22] investigated the importance of the HATCH score in the return of sinus rhythm after electrical cardioversion in 227 patients. The HATCH scoring system was found to indicate early clinical success. They reported that a HATCH score $>2$ was an indicator of failed electrical cardioversion with $77 \%$ sensitivity and $62 \%$ specificity.

Advanced age is associated with major cardiovascular events in patients with coronary artery disease [23]. It is also a risk factor for PoAF not only in heart surgery but also in noncardiac surgeries $[24,25]$. In this context, age was ranked by 1 point in the HATCH scoring system. It is thought that there is an increase in AF incidence due to structural shifts in the heart and atrial fibrosis related to advanced age [26]. In our study, age was significantly higher in the AF group in univariate analysis, but it was not an independent predictor of PoAF.

Two previous studies have investigated the relationship between the HATCH score and the development of PoAF after CABG. Emren et al. [8] studied 284 consecutive patients undergoing $\mathrm{CABG}$ of which $25 \%$ had PoAF. The HATCH scores of those with PoAF were significantly higher. In the ROC curve analysis, the AUC of the HATCH score was 0.773 (95\% CI 706-841, $p<0.001$ ). They also found that a HATCH score $>2$ indicated possible PoAF with $72 \%$ sensitivity and $75 \%$ specificity [ 8 ]. A study by Selvi et al. [27] included 369 patients who underwent CABG and detected PoAF in $27.9 \%$ of the patients; the patients were categorized as PoAF+ and PoAF-. $\mathrm{HATCH}$ score and age were significantly higher in the $\mathrm{PoAF}+$ group. In multivariate analysis, $\mathrm{HATCH}$ score and higher triglyceride levels were found to be independent predictors of PoAF. In ROC curve analysis, a HATCH score $>2$ indicated possible PoAF with $42 \%$ sensitivity and 70\% specificity [27].

In our study, we separated patients into 2 groups, those with HATCH score $>2$ (group 1) and those with HATCH score $\leq 2$ (group 2). We also calculated the SYNTAX score 
to evaluate the extensiveness of coronary artery disease. We found a significantly higher SYNTAX score in group 1. PoAF occurred in 42.3 and $22.2 \%$ of group 1 and 2 patients, respectively; the difference was statistically significant. Univariate analysis showed that age, high SYNTAX score, and HATCH score $>2$ were significant and (except for age) independent predictors of PoAF. In correlation analysis, we found a weak positive correlation between HATCH score and SYNTAX score.

\section{Limitations}

The small sample size and the retrospective design are the main limitations of this study. Twenty-four-hour ECG follow-up was performed during 5 days after surgery. After that, 12-lead ECG was performed in hospitalized patients who had complaints such as palpitation, dyspnea, or angina pectoris; 12-lead ECG was also performed daily in all inpatients until discharge. Therefore, PoAF might have been missed in some patients who did not report their complaints.

\section{Conclusion}

This study investigated the development of PoAF with reference to the HATCH score. The study demonstrated a correlation between the HATCH and SYNTAX scores.
These scores can be calculated for patients scheduled to undergo coronary artery bypass surgery, and the incidence of PoAF may be reduced via measures taken to prevent $A F$ in high-risk patients.

\section{Statement of Ethics}

The study was approved by the local ethics committee (approval No. 2019-2610/19.03.13).

\section{Disclosure Statement}

The authors have no conflicts of interest to declare.

\section{Funding Sources}

There are no funding sources to declare.

\section{Author Contributions}

M.E.: concept and design of the methodology described in this article, acquisition of data and analysis, literature research, manuscript writing, critical revision, and final editing of the paper. C.A.: literature research, manuscript writing, critical revision, and final editing of the paper.

\section{References}

1 Haghjoo M, Saravi M, Hashemi MJ, Hosseini S, Givtaj N, Ghafarinejad MH, et al. Optimal beta-blocker for prevention of atrial fibrillation after on-pump coronary artery bypass graft surgery: carvedilol versus etoprolol. Heart Rhythm. 2007 Sep;4(9): $1170-4$.

2 Mariscalco G, Engström KG. Atrial fibrillation after cardiac surgery: risk factors and their temporal relationship in prophylactic drug strategy decision. Int J Cardiol. 2008 Oct;129(3):354-62.

3 Smit MD, Van Gelder IC. New treatment options for atrial fibrillation: towards patient tailored therapy. Heart. 2011 Nov;97(21):1796802.

4 Sianos G, Morel MA, Kappetein AP, Morice MC, Colombo A, Dawkins K, et al. The SYNTAX Score: an angiographic tool grading the complexity of coronary artery disease. EuroIntervention. 2005 Aug;1(2):219-27.

5 Aktürk E, Aşkın L, Taşolar H, Türkmen S, Kaya H. Comparison of the predictive roles of risk scores of in-hospital major adverse cardiovascular events in patients with non-ST elevation myocardial infarction undergoing percutaneous coronary intervention. Med Princ Pract. 2018;27(5):459-65.

6 Geçmen Ç, Babür Güler G, Erdoğan E, Hatipoğlu S, Güler E, Yılmaz F, et al. SYNTAX score predicts postoperative atrial fibrillation in patients undergoing on-pump isolated coronary artery bypass grafting surgery. Anatol J Cardiol. 2016 Sep;16(9):655-61.

7 Chen K, Bai R, Deng W, Gao C, Zhang J, Wang $\mathrm{X}$, et al. HATCH score in the prediction of new-onset atrial fibrillation after catheter ablation of typical atrial flutter. Heart Rhythm. 2015 Jul;12(7):1483-9.

8 Emren V, Aldemir M, Duygu H, Kocabaş U, Tecer E, Cerit L, et al. Usefulness of HATCH score as a predictor of atrial fibrillation after coronary artery bypass graft. Kardiol Pol. 2016;74(8):749-53.

9 Camm AJ, Kirchhof P, Lip GY, Schotten U, Savelieva I, Ernst S, et al.; European Heart Rhythm Association; European Association for Cardio-Thoracic Surgery. Guidelines for the management of atrial fibrillation: the task force for the management of atrial fibrillation of the European Society of Cardiology (ESC). Eur Heart J. 2010 Oct;31(19):2369-429.
10 Kirchhof P, Benussi S, Kotecha D, Ahlsson A, Atar D, Casadei B, et al. 2016 ESC Guidelines for the management of atrial fibrillation developed in collaboration with EACTS. Eur J Cardiothorac Surg. 2016 Nov; 50(5):e1-88.

11 Mathew JP, Fontes ML, Tudor IC, Ramsay J, Duke P, Mazer CD, et al.; Investigators of the Ischemia Research and Education Foundation; Multicenter Study of Perioperative Ischemia Research Group. A multicenter risk index for atrial fibrillation after cardiac surgery. JAMA. 2004 Apr;291(14):1720-9.

12 Gungor H, Babu AS, Zencir C, Akpek M, Selvi $\mathrm{M}$, Erkan $\mathrm{MH}$, et al. Association of preoperative platelet-to-lymphocyte ratio with atrial fibrillation after coronary artery Bypass graft surgery. Med Princ Pract. 2017;26(2): $164-8$.

13 Mathew JP, Parks R, Savino JS, Friedman AS, Koch C, Mangano DT, et al. Atrial fibrillation following coronary artery bypass graft surgery: predictors, outcomes, and resource utilization. MultiCenter Study of Perioperative Ischemia Research Group. JAMA. 1996 Jul; 276(4):300-6. 
14 Hogue CW Jr, Creswell LL, Gutterman DD, Fleisher LA; American College of Chest Physicians. Epidemiology, mechanisms, and risks: american College of Chest Physicians guidelines for the prevention and management of postoperative atrial fibrillation after cardiac surgery. Chest. 2005 Aug; 128(2 Suppl):9S-16S.

15 Yadava M, Hughey AB, Crawford TC. Postoperative Atrial Fibrillation: Incidence, Mechanisms, and Clinical Correlates. Heart Fail Clin. 2016 Apr;12(2):299-308.

16 Aranki SF, Shaw DP, Adams DH, Rizzo RJ, Couper GS, VanderVliet M, et al. Predictors of atrial fibrillation after coronary artery surgery. Current trends and impact on hospital resources. Circulation. 1996 Aug;94(3): 390-7.

17 Walsh SR, Oates JE, Anderson JA, Blair SD, Makin CA, Walsh CJ. Postoperative arrhythmias in colorectal surgical patients: incidence and clinical correlates. Colorectal Dis. 2006 Mar;8(3):212-6.

18 Yadav M, Palmerini T, Caixeta A, Madhavan MV, Sanidas E, Kirtane AJ, et al. Prediction of coronary risk by SYNTAX and derived scores: synergy between percutaneous coro- nary intervention with taxus and cardiac surgery. J Am Coll Cardiol. 2013 Oct;62(14): 1219-30.

19 Serruys PW, Morice MC, Kappetein AP, Colombo A, Holmes DR, Mack MJ, et al.; SYNTAX Investigators. Percutaneous coronary intervention versus coronary-artery bypass grafting for severe coronary artery disease. $\mathrm{N}$ Engl J Med. 2009 Mar;360(10):961-72.

20 Cerit L, Duygu H, Gulsen K, Kemal HS, Ozcem B, Balcioglu O, et al. Is SYNTAX score predictive of atrial fibrillation after on-pump coronary artery bypass graft surgery? Korean Circ J. 2016 Nov;46(6):798-803.

21 Suenari K, Chao TF, Liu CJ, Kihara Y, Chen TJ, Chen SA, et al. Usefulness of $\mathrm{HATCH}$ score in the prediction of new-onset atrial fibrillation for Asians. Medicine (Baltimore). 2017 Jan;96(1):e5597.

22 Emren SV, Kocabaş U, Duygu H, Levent F, Şimşek EÇ, Yapan Emren Z, et al. The role of HATCH score in predicting the success rate of sinus rhythm following electrical cardioversion of atrial fibrillation. Kardiol Pol. 2016; 74(9):978-84.

23 Al-Zakwani I, Al Siyabi E, Alrawahi N, AlMulla A, Alnaeemi A, Shehab A, et al. Asso- ciation between peripheral artery disease and major adverse cardiovascular events in patients with acute coronary syndrome: Findings from the Gulf COAST Registry. Med Princ Pract. 2019;28(5):410-7.

24 Villareal RP, Hariharan R, Liu BC, Kar B, Lee VV, Elayda M, et al. Postoperative atrial fibrillation and mortality after coronary artery bypass surgery. J Am Coll Cardiol. 2004 Mar; 43(5):742-8

25 Vaporciyan AA, Correa AM, Rice DC, Roth JA, Smythe WR, Swisher SG, et al. Risk factors associated with atrial fibrillation after noncardiac thoracic surgery: analysis of 2588 patients. J Thorac Cardiovasc Surg. 2004 Mar; 127(3):779-86

26 Mariscalco G, Engström KG, Ferrarese S, Cozzi G, Bruno VD, Sessa F, et al. Relationship between atrial histopathology and atrial fibrillation after coronary bypass surgery. J Thorac Cardiovasc Surg. 2006 Jun;131(6): 1364-72.

27 Selvi M, Gungor H, Zencir C, Gulasti S, Eryilmaz U, Akgullu C, et al. A new predictor of atrial fibrillation after coronary artery bypass graft surgery: HATCH score. J Investig Med. 2018 Mar;66(3):648-52. 